\title{
Cobalt-Containing Nanoporous Nitrogen-Doped Carbon Nanocuboids from Zeolite Imidazole Frameworks for Supercapacitors
}

\author{
Yu Song ${ }^{1 \oplus}$, Mingyue Zhang ${ }^{1}$, Tianyu Liu ${ }^{2}{ }^{\oplus}$, Tianjiao Li $^{1}$, Di Guo ${ }^{1, *}$ and Xiao-Xia Liu ${ }^{1, *}$ \\ 1 Department of Chemistry, Northeastern University, Shenyang 110819, China \\ 2 Department of Chemistry, Virginia Tech, Blacksburg, VA 24060, USA \\ * Correspondence: guodi@mail.neu.edu.cn (D.G.); xxliu@mail.neu.edu.cn (X.-X.L.)
}

Received: 8 July 2019; Accepted: 30 July 2019; Published: 2 August 2019

check for updates

\begin{abstract}
Pyrolyzing metal-organic frameworks (MOFs) typically yield composites consisting of metal/metal oxide nanoparticles finely dispersed on carbon matrices. The blend of pseudocapacitive metal oxides and conductive metals, as well as highly porous carbon networks, offer unique opportunities to obtain supercapacitor electrodes with mutually high capacitances and excellent rate capabilities. Herein, we demonstrate nitrogen-doped carbon nanocuboid arrays grown on carbon fibers and incorporating cobalt metal and cobalt metal oxides. This composite was synthesized via pyrolysis of a chemical bath deposited MOF, cobalt-containing zeolite imidazole framework (Co-ZIF). The active materials for charge storage are the cobalt oxide and nitrogen-doped carbon. Additionally, the Co metal and the nanoporous carbon network facilitated electron transport and the rich nanopores in each nanocuboid shortened ion diffusion distance. Benefited from these merits, our Co-ZIF-derived electrode delivered an areal capacitance of $1177 \mathrm{mF} \mathrm{cm}^{-2}$ and excellent cycling stability of $\sim 94 \%$ capacitance retained after 20,000 continuous charge-discharge cycles. An asymmetric supercapacitor prototype having the Co-ZIF-derived hybrid material (positive electrode) and activated carbon (negative electrode) achieved a maximal volumetric energy density of $1.32 \mathrm{mWh} \mathrm{cm}^{-3}$ and the highest volumetric power density of $376 \mathrm{~mW} \mathrm{~cm}^{-3}$. This work highlights the promise of metal-metal oxide-carbon nanostructured composites as electrodes in electrochemical energy storage devices.
\end{abstract}

Keywords: metal-organic frameworks; zeolite-imidazole frameworks; cobalt; carbon; nanoporous; supercapacitors

\section{Introduction}

Developing nanomaterials for electrochemical energy storage is among the forefront of materials research [1-5]. A plethora of nanostructured transition metal oxides, for example, manganese dioxide $\left(\mathrm{MnO}_{2}\right)$ [6-8], iron oxide $\left(\mathrm{Fe}_{2} \mathrm{O}_{3}\right)$ [9-11], molybdenum trioxide $\left(\mathrm{MoO}_{3}\right)$ [12,13], tungsten oxide $\left(\mathrm{WO}_{3}\right)$ [14], and cobalt oxides $\left(\mathrm{Co}_{3} \mathrm{O}_{4}\right.$ and $\left.\mathrm{CoO}\right)[15,16]$, are potent electrode materials for secondary batteries and supercapacitors, thanks to their characteristics of high theoretical capacities or capacitances, earth abundance, low toxicity, and cost-effectiveness. One major challenge of these nanomaterials for supercapacitors is that their experimental capacities or capacitances are far below the theoretical values because the electrically insulating or semiconducting natures dramatically impede fast electron transport and ion diffusion, which are the two prerequisites for excellent rate capabilities and power densities [17-19].

Strategies to mitigate the intrinsic drawbacks of metal oxide electrodes involve two means. The first method is to incorporate metal oxides into highly conductive scaffolds, such as carbon and metals, to form composite electrodes. For example, Li et al. sandwiched a thin Mn metal layer between 
two $\mathrm{MnO}_{2}$ layers for capacitive charge storage [20]. The metal $\mathrm{Mn}$ central layer served as an electrically conductive substrate to remedy the negative impact of the poor electrical conductivity of $\mathrm{MnO}_{2}$. The second strategy is to construct hierarchically porous architectures with pore sizes spanning from sub-nanometers to hundreds of micrometers [21]. These unique architectures are beneficial to speed up ion diffusion, facilitate electrolyte ion infiltration as well as enhance active surface areas [22,23]. Song and Liu et al. devised a glucose-assisted hydrothermal method to fabricate mesoporous iron(III) oxide films with tunable pore sizes [9]. With $1 \mu \mathrm{m}$ in thickness and $5 \mathrm{mg} \mathrm{cm}^{-2}$ in mass loading, the mesoporous hematite electrode reached $1502 \mathrm{mF} \mathrm{cm}^{-2}$ at $1 \mathrm{~mA} \mathrm{~cm}^{-2}$, approximately two to three times higher than other hematite materials with similar mass loadings.

We turned our attention to metal-organic frameworks (MOFs), a family of crystalline coordination compounds consisting of organic ligands and metal nodes [24,25], to address the bottlenecks above for metal-oxide-based supercapacitor electrodes. These nanomaterials, upon thermal annealing, produced metal or metal oxide nanoparticles (from metal nodes) uniformly embedded in carbon matrices (from organic ligands). This strategy to fabricate metal-carbon composites has advantages of dispersion uniformity compared to evaporation/sputtering [26] or electrodeposition [27]. This configuration is beneficial for high-performance charge storage: The electrically conductive carbon networks, as well as metal nanoparticles, alleviate the limited electrical conductivity of metal oxides. The high porosities inherited from MOFs allow for rapid electrolyte infiltration and ion diffusion to ensure excellent power densities. The uniformly distributed metal oxide nanoparticles sustain large contact areas with electrolyte ions and maintain high capacitances and energy densities.

In this work, we synthesized a cobalt-containing MOF, termed zinc-imidazole framework-67 (Co-ZIF), as a starting material through chemical bath deposition on carbon cloth fibers. Utilizing facile thermal annealing under $\mathrm{N}_{2}$ atmosphere, we converted the $\mathrm{Co}$-ZIF nanocuboids into nanoporous, $\mathrm{N}$-doped carbon nanocuboids supporting finely dispersed cobalt metal and cobalt oxide nanoparticles. The metal $\mathrm{Co}$ and $\mathrm{N}$-doped carbon provide electron transport expressways, and the nanopores in each nanocuboid ensure low-impedance ion diffusion. As a result, the hybrid material achieved an areal capacitance of $1200 \mathrm{mF} \mathrm{cm}{ }^{-2}$ at $1 \mathrm{~mA} \mathrm{~cm}^{-2}$, and highly stable performance with more than $90 \%$ capacitance maintained after 20,000 charge-discharge cycles. Coupled with activated carbon (a negative electrode), our composite material is also a potent positive electrode of an asymmetric supercapacitor prototype.

\section{Materials and Methods}

\subsection{Materials}

Carbon cloth was obtained from USA Fuel Cell Earth Company (Woburn, MA, USA). Concentrated nitric acid $\left(\mathrm{HNO}_{3}\right)$, cobalt nitrate hexahydrate $\left[\mathrm{Co}\left(\mathrm{NO}_{3}\right)_{2} \cdot 6 \mathrm{H}_{2} \mathrm{O}\right], 2$-methylimidazole, $\mathrm{N}$-methyl-2-pyrrolidone (NMP), polyvinylidene fluoride (PVDF), activated carbon (AC), and potassium hydroxide $(\mathrm{KOH})$ were all provided by Sinopharm Chemical Reagent Co., Ltd. (Shenyang, China), and used as received.

\subsection{Fabrication of Hybrid Electrode Materials}

First, a piece of carbon cloth $\left(1 \times 2 \mathrm{~cm}^{2}\right)$ was hydrothermally heated at $120^{\circ} \mathrm{C}$ for $2 \mathrm{~h}$ in a Teflon-lined autoclave containing a $30 \mathrm{wt}$. $\% \mathrm{HNO}_{3}$ aqueous solution to increase the surface hydrophilicity. Second, $1.3 \mathrm{~g}$ 2-methylimidazole and $0.582 \mathrm{~g} \mathrm{Co}\left(\mathrm{NO}_{3}\right)_{2} \cdot 6 \mathrm{H}_{2} \mathrm{O}$ were dissolved in $50 \mathrm{~mL}$ deionized water stirred at room temperature for $30 \mathrm{~min}$ to form a clear blue solution. Third, the treated carbon cloth was soaked in the solution at $35^{\circ} \mathrm{C}$ for $1 \mathrm{~h}$. Afterward, the carbon cloth was washed with alcohol and deionized water to remove solution residues, and dried in a vacuum oven at $50{ }^{\circ} \mathrm{C}$ for $10 \mathrm{~h}$. Last, the carbon cloth was annealed in a tube furnace at $350{ }^{\circ} \mathrm{C}, 450{ }^{\circ} \mathrm{C}$, or $550{ }^{\circ} \mathrm{C}$ for $1 \mathrm{~h}$ under $\mathrm{N}_{2}$ with a ramp rate of $5{ }^{\circ} \mathrm{C} \mathrm{min}{ }^{-1}$, leading to electrodes denoted as Co-ZIF-X, where $X=350,450$, and 550 representing the thermal annealing temperature in ${ }^{\circ} \mathrm{C}$. 


\subsection{Assembly of Asymmetric Supercapacitors}

The practical electrochemical performances of the Co-ZIF-450 electrodes were evaluated in asymmetric supercapacitor prototypes possessing the Co-ZIF-450 positive electrode and an AC negative electrode. The AC negative electrode was prepared by uniformly mixing $2 \mathrm{~g} \mathrm{AC}, 0.025 \mathrm{~g}$ acetylene black, and $0.8 \mathrm{~g}$ NMP in an agate mortar for $2 \mathrm{~h}$. The resultant black slurry was spread onto a piece of carbon cloth current collector. After soaking the positive and negative electrodes in $2 \mathrm{M} \mathrm{KOH}$ aqueous solution for $10 \mathrm{~min}$, we sandwiched a piece of filter paper absorbed with the $\mathrm{KOH}$ solution between the electrodes. Afterward, the supercapacitor was wrapped and sealed by parafilm to avoid electrolyte leakage. The volume of the asymmetric supercapacitor, including the parafilm packing, was $\sim 0.9 \mathrm{~mm}^{3}(10 \mathrm{~mm} \times 10 \mathrm{~mm} \times 0.09 \mathrm{~mm})$.

\subsection{Characterizations}

Carl Zeiss Ultra Plus scanning electron microscopy (SEM, Carl Zeiss, Germany) imaged the morphologies. Fourier transform infrared spectroscopy (FTIR) was conducted by an infrared spectrometer (VERTEX70, Bruker Optics, Billerica, MA, USA). X-ray diffraction (XRD) was performed by a (PANalytical X'Pert Pro, PANalytical Inc., Netherlands) X-ray powder diffractometer. X-ray photoelectron spectroscopy (XPS) were collected by an XPS spectrometer (ESCALAB 250Xi, Thermo Scientific Inc., Waltham, MA, USA) with $\mathrm{Al} K_{\alpha}$ radiation as the source of excitation. The binding energies of the XPS data were calibrated using $\mathrm{C} 1 \mathrm{~s}$ peak at $284.6 \mathrm{eV}$ as the reference. Electrochemical performances of the electrodes were investigated by a VMP3 multichannel electrochemical workstation with a three-electrode testing configuration using the material of interest as the working electrode, a $\mathrm{Hg} / \mathrm{HgO}$ electrode as the reference electrode, and a piece of carbon cloth as the counter electrode. The details of the methylene blue (MB) adsorption experiments for surface area determination were included in the discussion associated with Figure S3 in the Supplementary Materials.

\section{Results and Discussion}

We utilized a chemical bath deposition technique to grow cobalt-containing ZIF-67 (Co-ZIF) sheets onto commercial carbon cloth, and annealed the coated carbon cloth under $\mathrm{N}_{2}$ to convert $\mathrm{Co}-\mathrm{ZIF}$ to cobalt- and cobalt oxide-incorporated porous carbon electrodes (Figure 1a). In the FI-IR spectrum of Co-ZIF (Figure 1b), the peaks between 400 and $1700 \mathrm{~cm}^{-1}$ are the fingerprints of Co-ZIF [28]: The main vibration modes at 426, 1146 and 1302 , and $1569 \mathrm{~cm}^{-1}$ correspond to the $\mathrm{Co}-\mathrm{N}$ stretching, $\mathrm{C}-\mathrm{H}$ vibration, and $\mathrm{C}=\mathrm{N}$ vibration, respectively [29]. Additionally, the XRD pattern of $\mathrm{Co}-\mathrm{ZIF}$ (Figure 1c) matched with the standard one [28], confirming the successful growth of Co-ZIF. Annealing Co-ZIF at $350{ }^{\circ} \mathrm{C}$ for $1 \mathrm{~h}$ partially decomposed its ligands to amorphous carbonaceous compounds, as proven by the broad diffraction peak spanning from $10^{\circ}$ to $30^{\circ}$. Further elevating the annealing temperature completely converted Co-ZIF to cobalt-based compounds and amorphous carbon. While the broad peak of amorphous carbon was still present, there were three new peaks at $\sim 36.5^{\circ}, 42.4^{\circ}$, and $44.4^{\circ}$. The first two peaks were from the (111) and (200) planes of CoO (JCPDS \#09-0402), and the last one was the diffraction peak of the Co (111) plane (JCPDS \#01-1259). Furthermore, we used the Scherrer equation to evaluate the crystal sizes of $\mathrm{CoO}$ and $\mathrm{Co}$ :

$$
D=\frac{K \lambda}{\beta(\theta) \cos (\theta)}
$$

where $D$ is the crystal size; $K$ is the Scherrer's constant $(0.89) ; \lambda$ is the wavelength of the $X$-ray $(0.15405 \mathrm{~nm}) ; \theta$ is the diffraction angle, and $\beta(\theta)$ is full width at half maximum (FWHM) of the X-ray diffraction peak $(\theta)$. The crystal size of $\mathrm{CoO}$ in Co-ZIF-450 calculated based on the (111) diffraction peak of CoO (JCPDS \#09-0402) is $\sim 10.7 \mathrm{~nm}$, while that of Co nanoparticles based on the (111) diffraction peak of Co (JCPDS \#01-1259) is $\sim 17.8 \mathrm{~nm}$. 
a

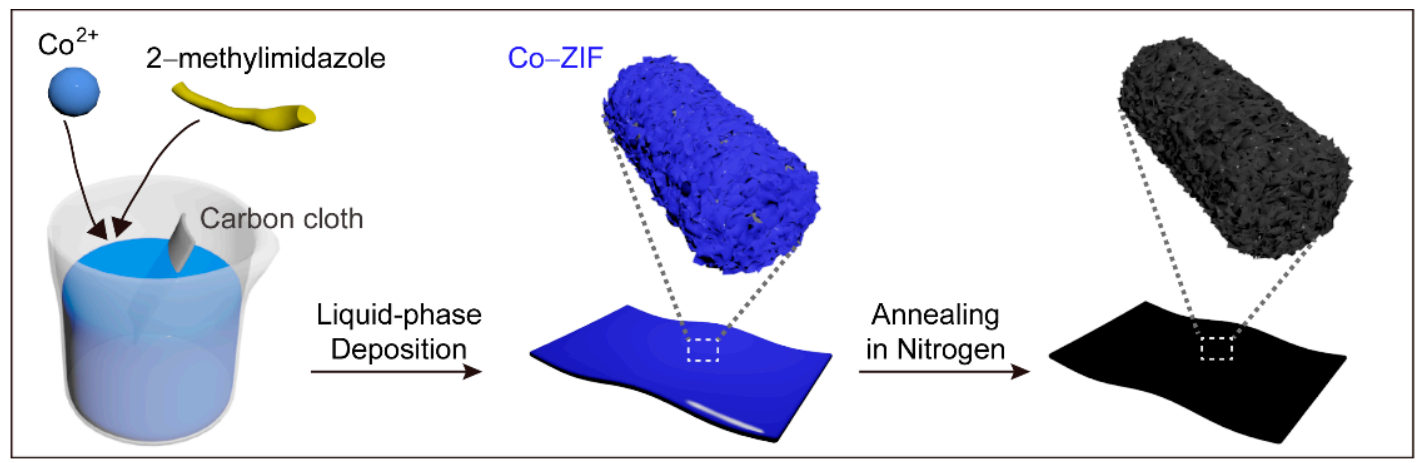

b

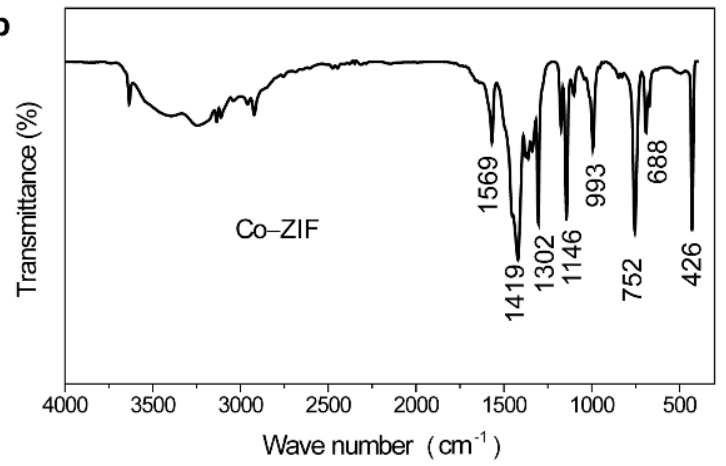

d
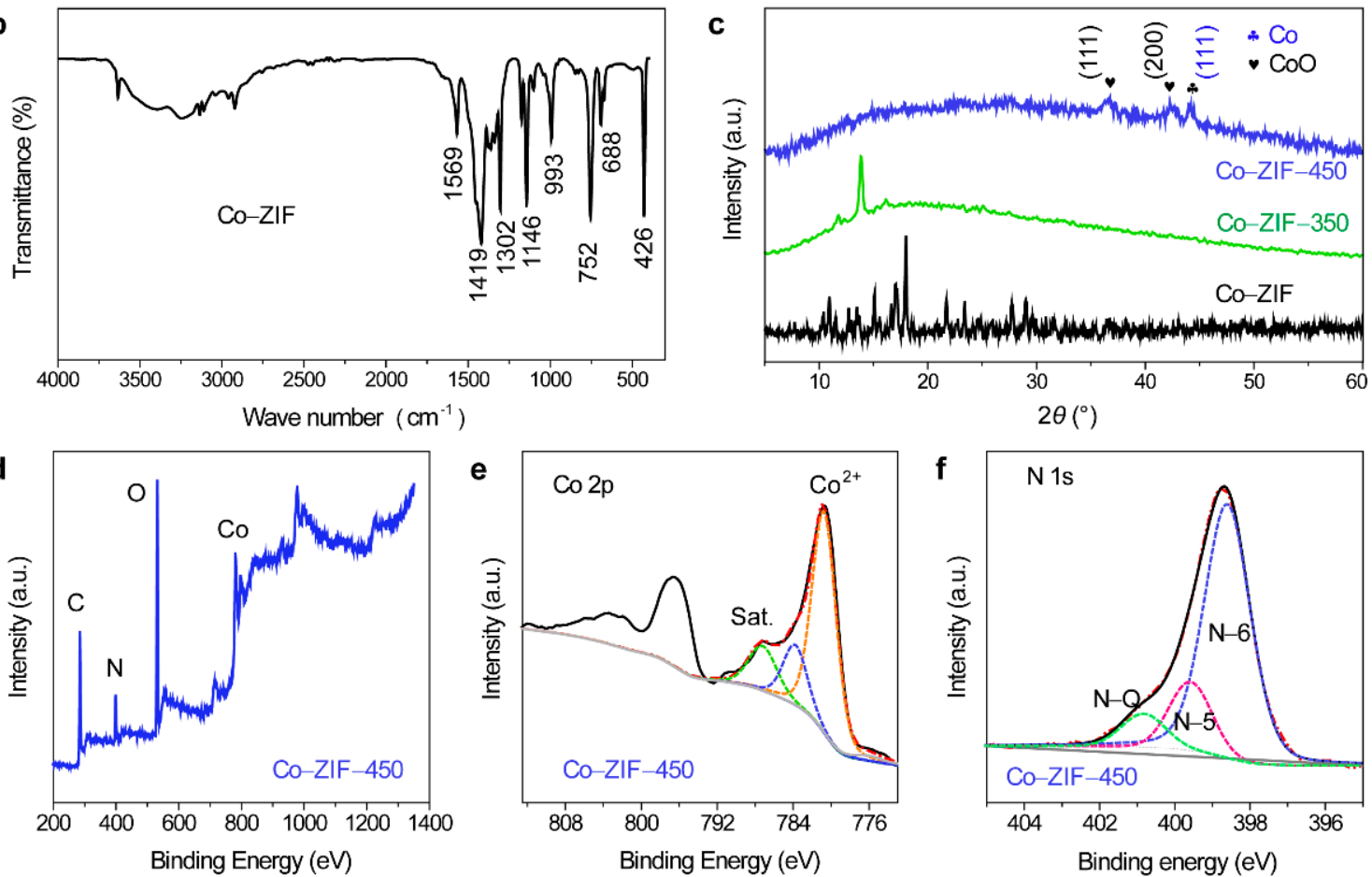

Figure 1. (a) Schematic illustrating the synthesis steps of cobalt-containing zeolite imidazole framework (Co-ZIF-X; X=thermal annealing temperature) on carbon cloth substrate. (b) FTIR spectrum of Co-ZIF.

(c) XRD patterns of Co-ZIF, Co-ZIF-350, and Co-ZIF-450. (d) XPS survey spectrum of Co-ZIF-450.

(e) Co $2 p$ XPS spectrum of Co-ZIF-450. (f) N $1 s$ spectrum of Co-ZIF-450. For the XPS spectra, the solid black lines are experimental data, the solid gray lines are baselines, and the dashed lines are deconvoluted peaks.

XPS probed the elemental composition of the product (Co-ZIF-450) after the $450{ }^{\circ} \mathrm{C}$ annealing. The survey spectrum disclosed that Co-ZIF-450 contained elements of C, O, N, and Co (Figure 1d). We believed that the nitrogen element must come from the nitrogen-doped carbon matrix because XRD showed no cobalt nitride. The main peak at $780.1 \mathrm{eV}$ in the Co $2 p$ XPS peak was from CoO [28], while the peaks at $776.1 \mathrm{eV}$ and $783.9 \mathrm{eV}$ presented the existence of $\mathrm{Co}$ metal and $\mathrm{Co}_{3} \mathrm{O}_{4}$, respectively (Figure 1e) [30]. The strong peak of $\mathrm{CoO}$ marked that the $\mathrm{Co}^{2+}$ ions in $\mathrm{Co}-\mathrm{ZIF}$ were mostly oxidized to low-valence-state compound, $\mathrm{CoO}$ in the air, a phenomenon also observed in other works [30-32]. In addition, three synthetic peaks, pyrrolic $\mathrm{N}(\mathrm{N}-5)$, pyridinic $\mathrm{N}(\mathrm{N}-6)$, and quaternary $\mathrm{N}(\mathrm{N}-\mathrm{Q})$ constituted the $\mathrm{N} 1$ s peak of $\mathrm{Co}-\mathrm{ZIF}-450$, again proving the $\mathrm{N}$ doping nature of the carbonaceous matrix since no peaks of $\mathrm{Co}-\mathrm{N}$ bonds appeared. These $\mathrm{N}$-moieties are known to offer pseudocapacitance and facilitate electron transfer at electrode/electrolyte interfaces [33].

We utilized SEM to investigate how the morphology evolved before and after the thermal annealing. Co-ZIF was composed of nanocuboids uniformly grown on carbon cloth fibers (Figure 2a). 
Each nanocuboid was $\sim 200 \mathrm{~nm}$ thick (Figure $2 \mathrm{~b}$ ) and $\sim 2 \mu \mathrm{m}$ long (Figure S1, Supplementary Materials). Annealing Co-ZIF at $350{ }^{\circ} \mathrm{C}$ showed little deviation in morphology from its original state. The decomposition of the organic ligands of Co-ZIF perforated each nanocuboid when the annealing temperature was elevated to $450{ }^{\circ} \mathrm{C}$ and $550{ }^{\circ} \mathrm{C}$. Additionally, the neighboring nanocuboids of Co-ZIF-550 aggregated into bundles, which could have resulted from structural collapse during the annealing step. The aggregation is unfavorable for rapid charge storage since it elongates the distances of electron transport and ion diffusion [34]. For all cases, the SEM images showed no large particles and proved that cobalt and cobalt oxide were finely dispersed without severe agglomerating into SEM-detectable particles. The fine dispersion was also evidenced by the uniform element distributions unveiled by the elemental mappings of SEM (Figure S2, Supplementary Materials).

Methylene blue adsorption experiment gauged the surface areas of Co-ZIF-350, Co-ZIF-450, and Co-ZIF-550 at room temperature. Using the absorption at $650 \mathrm{~nm}$ of the dye-desorbed samples (Figure S3, Supplementary Materials), we evaluated that the surface area of Co-ZIF-450 reached $61.6 \mathrm{~m}^{2} \mathrm{~g}^{-1}$, while those of Co-ZIF-350 and Co-ZIF-550 were $30.6 \mathrm{~m}^{2} \mathrm{~g}^{-1}$ and $22 \mathrm{~m}^{2} \mathrm{~g}^{-1}$, respectively. The lowest surface area of Co-ZIF-550 marked the negative influence of nanocuboid aggregation.
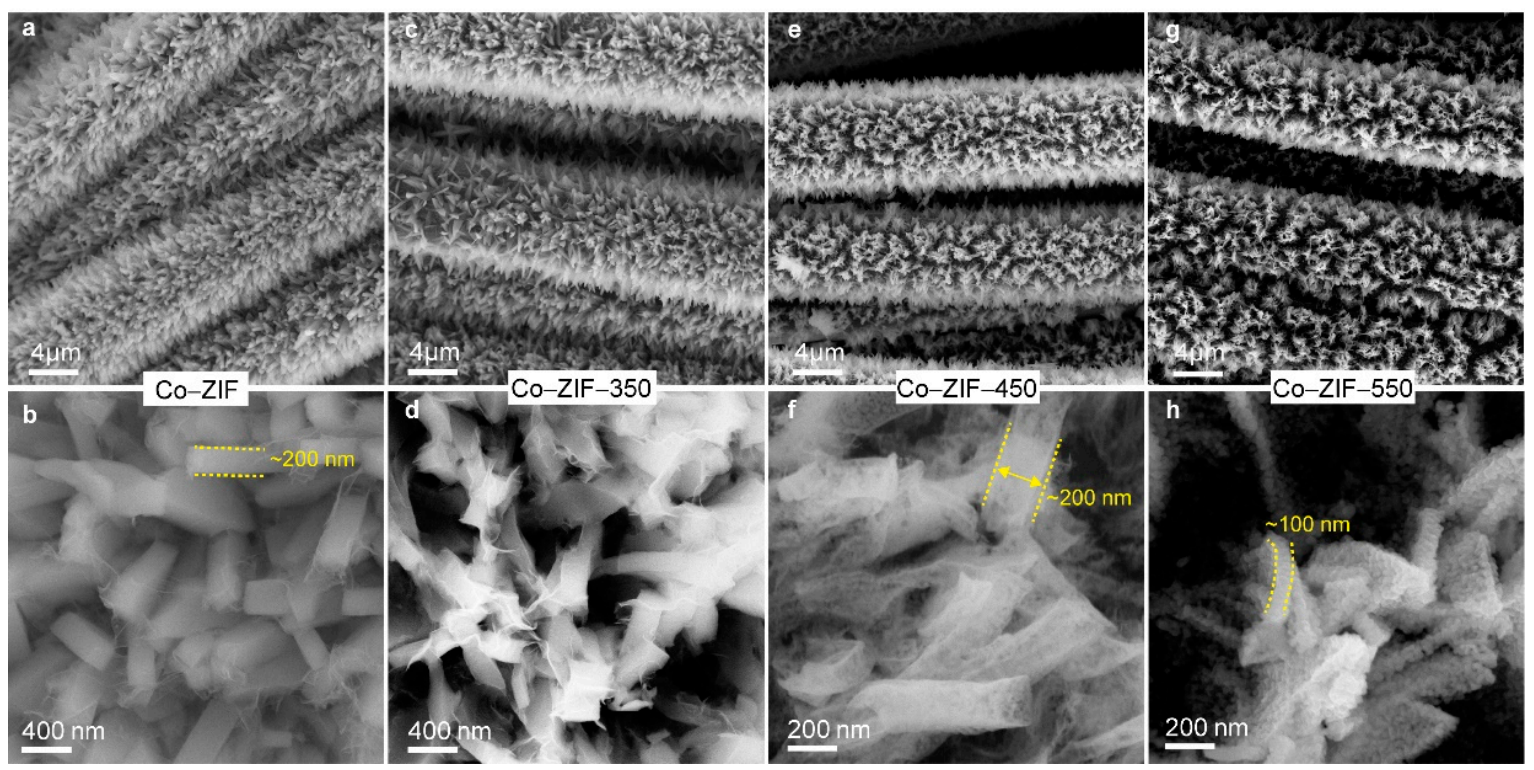

Figure 2. SEM images of (a,b) Co-ZIF; (c,d) Co-ZIF-350; (e,f) Co-ZIF-450; (g,h) Co-ZIF-550.

The dashed yellow lines highlight the thicknesses of corresponding nanocuboids.

Co-ZIF-450 exhibited the best electrochemical performance among all the tested samples. The enclosed area by the cyclic voltammetry (CV) curve of Co-ZIF-450 was appreciably larger than those of Co-ZIF-350 and Co-ZIF-550 (Figure 3a), indicating that Co-ZIF-450 had the largest capacitance. The two pairs in the CV curves, one within $0.1-0.2 \mathrm{~V}$ (vs. $\mathrm{Hg} / \mathrm{HgO}$ ) and another one at $\sim 0.5 \mathrm{~V}$ (vs. $\mathrm{Hg} / \mathrm{HgO}$ ), resulted from the following redox reactions [15]:

$$
\begin{aligned}
& 3 \mathrm{CoO}+2 \mathrm{OH}^{-} \leftrightarrow \mathrm{Co}_{3} \mathrm{O}_{4}+\mathrm{H}_{2} \mathrm{O}+2 e^{-} \\
& \mathrm{Co}_{3} \mathrm{O}_{4}+\mathrm{OH}^{-}+\mathrm{H}_{2} \mathrm{O} \leftrightarrow 3 \mathrm{CoOOH}+e^{-}
\end{aligned}
$$

The broad redox peaks demonstrated pseudocapacitive behavior. Additionally, the pseudocapacitive characteristic of Co-ZIF-450 was reflected from the symmetric and plateau-free galvanostatic charge-discharge curves (Figure 3b). Among all the tested electrodes, Co-ZIF-450 achieved the highest areal capacitance of $1177 \mathrm{mF} \mathrm{cm}{ }^{-2}$ at $1 \mathrm{~mA} \mathrm{~cm}^{-2}$ (Figure 3c), corresponding to a gravimetric capacitance of $370 \mathrm{~F} \mathrm{~g}^{-1}$ (based on the active mass of $\sim 3.2 \mathrm{mg} \mathrm{cm}^{-2}$, Figure S4, Supplementary Materials). Remarkably, these values surpassed those of the previously reported cobalt 
oxide-based pseudocapacitive electrodes, such as MOF-derived dendrite-like $\mathrm{Co}_{3} \mathrm{O}_{4}$ nanomaterial (207.8 F g ${ }^{-1} @ 0.5 \mathrm{~A} \mathrm{~g}^{-1}$ ) [35], Co-based MOF (179 F g ${ }^{-1} @ 10 \mathrm{mV} \mathrm{s}^{-1}$ ) [36] and MOF-derived porous $\mathrm{Co}_{3} \mathrm{O}_{4}\left(150 \mathrm{~F} \mathrm{~g}^{-1} @ 1 \mathrm{~A} \mathrm{~g}^{-1}\right)$ [37]. When the current density increased 20 times to $20 \mathrm{~mA} \mathrm{~cm}^{-2}, \mathrm{Co}-\mathrm{ZIF}-450$ still acquired an areal capacitance of $640 \mathrm{mF} \mathrm{cm}^{-2}$ (equivalent to $54.4 \%$ capacitance retention).
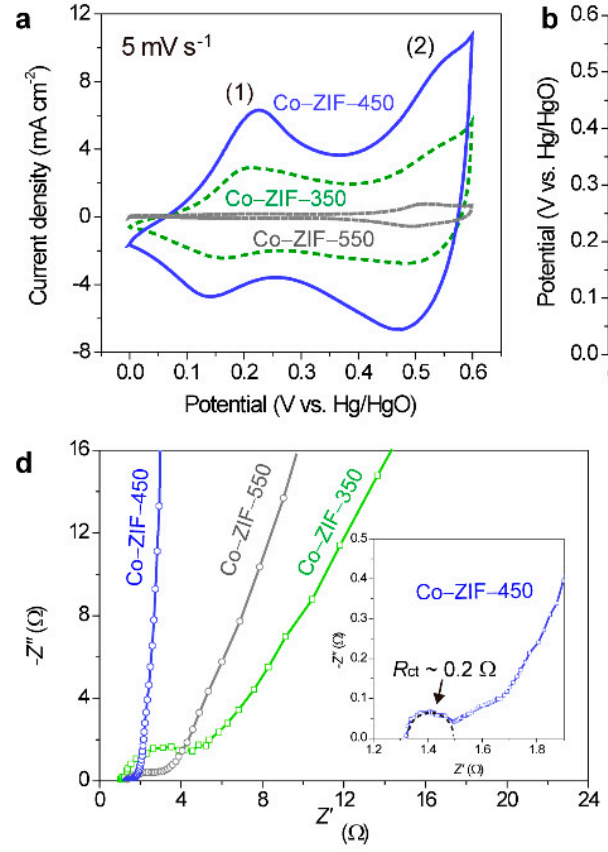
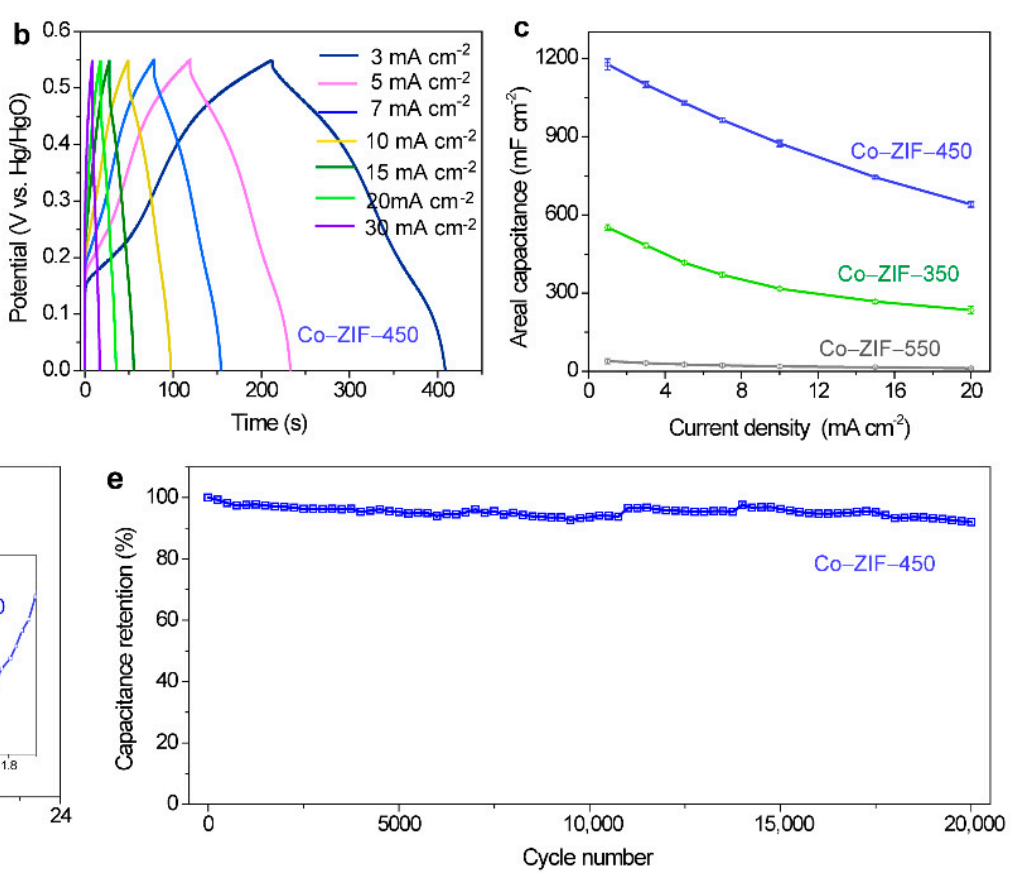

Figure 3. Electrochemical performances collected in $2 \mathrm{M}$ aqueous $\mathrm{KOH}$ electrolytes via a three-electrode testing configuration. (a) Cyclic voltammetry (CV) curves of Co-ZIF-350, Co-ZIF-450, and Co-ZIF-550 at $5 \mathrm{mV} \mathrm{s}^{-1}$. (b) Galvanostatic charge and discharge curves of Co-ZIF-450 at different current densities. (c) Comparison of areal capacitances of Co-ZIF-350, Co-ZIF-450, and Co-ZIF-550 at 1-20 $\mathrm{mA} \mathrm{cm}^{-2}$. The error bars are standard deviations determined at least in triplicate. (d) Nyquist plots of Co-ZIF-350, Co-ZIF-450, and Co-ZIF-550. Inset: Enlarged view of the high- to middle-frequency domains of the Nyquist plot of Co-ZIF-450. (e) Cycling stability of Co-ZIF-450 after 20,000 consecutive charge-discharge cycles.

Co-ZIF-350 and Co-ZIF-550 were unable to compete with Co-ZIF-450. When the current density changed from 1 to $20 \mathrm{~mA} \mathrm{~cm}{ }^{-2}$, the areal capacitance of Co-ZIF-350 decreased from $553 \mathrm{mF} \mathrm{cm}^{-2}$ to $235 \mathrm{mF} \mathrm{cm}^{-2}$, and that of Co-ZIF-550 dropped from $37 \mathrm{mF} \mathrm{cm}^{-2}$ to $11 \mathrm{mF} \mathrm{cm}^{-2}$. We speculated that Co-ZIF-350 suffered from the low electrical conductivity due to the incomplete decomposition of Co-ZIF. The electrochemical performance of Co-ZIF-550 was restricted by the structural collapse as discussed earlier.

The Nyquist plot of Co-ZIF-450 disclosed more insights into its electrochemical performance. The plot displayed a semi-circle in the high-frequency domain and a vertical spike in the low-frequency region (Figure $3 \mathrm{~d}$ ), resembling the plots of electrodes having typical capacitive behaviors [38]. Both the equivalent series resistance $\left(R_{\mathrm{S}}\right.$, the intercept of the plot with $Z^{\prime}$-axis) and the charge-transfer resistance ( $R_{\mathrm{ct}}$, the diameter of the semi-circle) of Co-ZIF-450 are small ( 1.3 $\Omega$ and $\sim 2 \Omega$, respectively). The blending of electrically conductive carbon matrix and Co metal eased the electron transport in the electrode and accounted for the small $R_{\mathrm{s}}$. Additionally, the nanoporous nanocuboid arrays facilitated ion diffusion. This factor, together with the rapid electron transport, decreased $R_{\mathrm{ct}}$. The $R_{\mathrm{ct}}$ of Co-ZIF-350, Co-ZIF-450, and Co-ZIF-550 were about $4.0 \Omega, 0.2 \Omega$, and $2.0 \Omega$, respectively. The relatively large $R_{\mathrm{ct}}$ of Co-ZIF-350 came from the incomplete decomposition that yielded little Co metal particles and carbon for fast electron conduction near the electrodelelectrolyte interfaces. The $R_{\mathrm{ct}}$ of Co-ZIF-550 
raised slightly, as a result of structural collapse that retarded the redox reactions involving electron-ion interactions (evidenced from the $\mathrm{CV}$ result).

The capacitance of Co-ZIF-450 was maintained at $93.5 \%$ after 10,000 repetitive charge-discharge cycles, which is comparably good than those of Co-ZIF-350 (95.6\%) and Co-ZIF-550 (93.6\%) after identical cycle numbers (Figure S5, Supplementary Materials). Significantly, the capacitance of Co-ZIF-450 was kept stable with no capacitance loss after 20,000 continuous charge-discharge cycles (Figure 3e).

Taking together, we ascribed the outstanding electrochemical performance of Co-ZIF-450 to four reasons: First, the metal $\mathrm{Co}$ and $\mathrm{N}$-doped carbon constructed a highly conductive network which facilitated electron transport in the electrode. Second, the uniformly distributed pores in each nanocuboid acted as electrolyte ion reservoirs that shortened the diffusion distances to electrode surfaces and thus, facilitated ion diffusion. Third, the in-situ growth of nanocuboids eliminated the need for electrically insulating binders and reduced the contact resistance between the current collector (carbon cloth) and the active materials. Fourth, the soft carbon matrix effectively buffered the mechanical stress imposed by cobalt oxide during charge and discharge processes, leading to the durable charge-storage performance.

To evaluate the potential of Co-ZIF-450 under realistic working conditions, we assembled an asymmetric supercapacitor prototype using Co-ZIF-450 as the positive electrode and activated carbon powders (AC) coated on carbon cloth as the negative electrode (the electrochemical activities of the AC electrode is summarized in Figure S6, Supplementary Materials). The asymmetric device is denoted as AC//Co-ZIF-450. The stable potential windows of Co-ZIF-450 and activated carbon were 0 to $0.55 \mathrm{~V}$ (vs. $\mathrm{Hg} / \mathrm{HgO}$ ) and -1.0 to $0 \mathrm{~V}$ (vs. $\mathrm{Hg} / \mathrm{HgO}$ ), respectively (Figure $4 \mathrm{a}$ ), adding up to a theoretical overall potential window of $1.55 \mathrm{~V}$ for AC//Co-ZIF-450. Indeed, AC//Co-ZIF-450 displayed CV curves devoid of a sharp increase in current at potentials up to $1.55 \mathrm{~V}$ (Figure $4 \mathrm{~b}$ ). Its cyclic voltammogram also enclosed larger area than those of AC//Co-ZIF-350 and AC//Co-ZIF-550 (Figure S7, Supplementary Materials), showing the highest capacitance $\left(102,288,28.6 \mathrm{mF} \mathrm{cm}{ }^{-2}\right.$ for AC//Co-ZIF-350, AC//Co-ZIF-450, and AC//Co-ZIF-550, respectively). The symmetric galvanostatic charge and discharge curves suggested good Coulombic efficiency, and the sloping feature marked the capacitive nature of the prototype (Figure 4c). Outstandingly, our asymmetric device achieved a high volumetric capacitance of $4 \mathrm{~F} \mathrm{~cm}^{-3}$ at $1 \mathrm{~mA} \mathrm{~cm}^{-2}$ (Figure $4 \mathrm{~d}$ ), surpassing those of the state-of-the-art supercapacitors with similar thicknesses, including $\mathrm{Co}_{9} \mathrm{~S}_{8}$ nanorod $/ / \mathrm{Co}_{3} \mathrm{O}_{4} @ \mathrm{RuO}_{2}\left(3.42 \mathrm{~F} \mathrm{~cm}^{-3} @\right.$ $\left.2.5 \mathrm{~mA} \mathrm{~cm}^{-2}\right)$ [39], $\mathrm{Co}_{11}\left(\mathrm{HPO}_{3}\right)_{8}(\mathrm{OH})_{6}-\mathrm{Co}_{3} \mathrm{O}_{4} / /$ graphene $\left(1.84 \mathrm{~F} \mathrm{~cm}^{-3} @ 0.5 \mathrm{~mA} \mathrm{~cm}^{-2}\right)$ [40], and $\mathrm{VO}_{\mathrm{x}} / / \mathrm{VN}$ $\left(1.35 \mathrm{~F} \mathrm{~cm}^{-3} @ 0.5 \mathrm{~mA} \mathrm{~cm}^{-2}\right)$ [22]. The volumetric capacitance remained $2.15 \mathrm{~F} \mathrm{~cm}^{-3}$ at $40 \mathrm{~mA} \mathrm{~cm}^{-2}$. Besides, the prototype maintained $\sim 91 \%$ of its initial capacitance after being subjected to 20,000 continuous charge-discharge cycles. In terms of energy-storage capacity, our prototype presented a volumetric energy density of $1.32 \mathrm{mWh} \mathrm{cm}^{-3}$ at a power density of $9.4 \mathrm{~mW} \mathrm{~cm}^{-3}$, and $0.73 \mathrm{mWh} \mathrm{cm} \mathrm{cm}^{-3}$ at $376 \mathrm{~mW} \mathrm{~cm}^{-3}$, higher than supercapacitors with comparable volumes [5,39-45], e.g., $\mathrm{Co}_{9} \mathrm{~S}_{8}$ nanorod// $\mathrm{Co}_{3} \mathrm{O}_{4} @ \mathrm{RuO}_{2}\left(1.21 \mathrm{mWh} \mathrm{cm}{ }^{-3} @ 13.29 \mathrm{~mW} \mathrm{~cm}{ }^{-3}\right)$ [39], $\mathrm{NaCoPO}_{4}-\mathrm{Co}_{3} \mathrm{O}_{4} / /$ graphene (0.39 mWh cm $\left.\mathrm{m}^{-3} @ 5 \mathrm{~mW} \mathrm{~cm}{ }^{-3}\right)$ [45], $\mathrm{Co}_{11}\left(\mathrm{HPO}_{3}\right)_{8}(\mathrm{OH})_{6}-\mathrm{Co}_{3} \mathrm{O}_{4} / /$ graphene $\left(0.48 \mathrm{mWh} \mathrm{cm}{ }^{-3} @\right.$ $\left.3.5 \mathrm{~mW} \mathrm{~cm}^{-3}\right)$ [40], and $\mathrm{PPy} / / \mathrm{MnO}_{2}\left(0.8 \mathrm{mWh} \mathrm{cm}^{-3} @ 12.85 \mathrm{~mW} \mathrm{~cm}^{-3}\right)$ [41] (Figure 4f). 

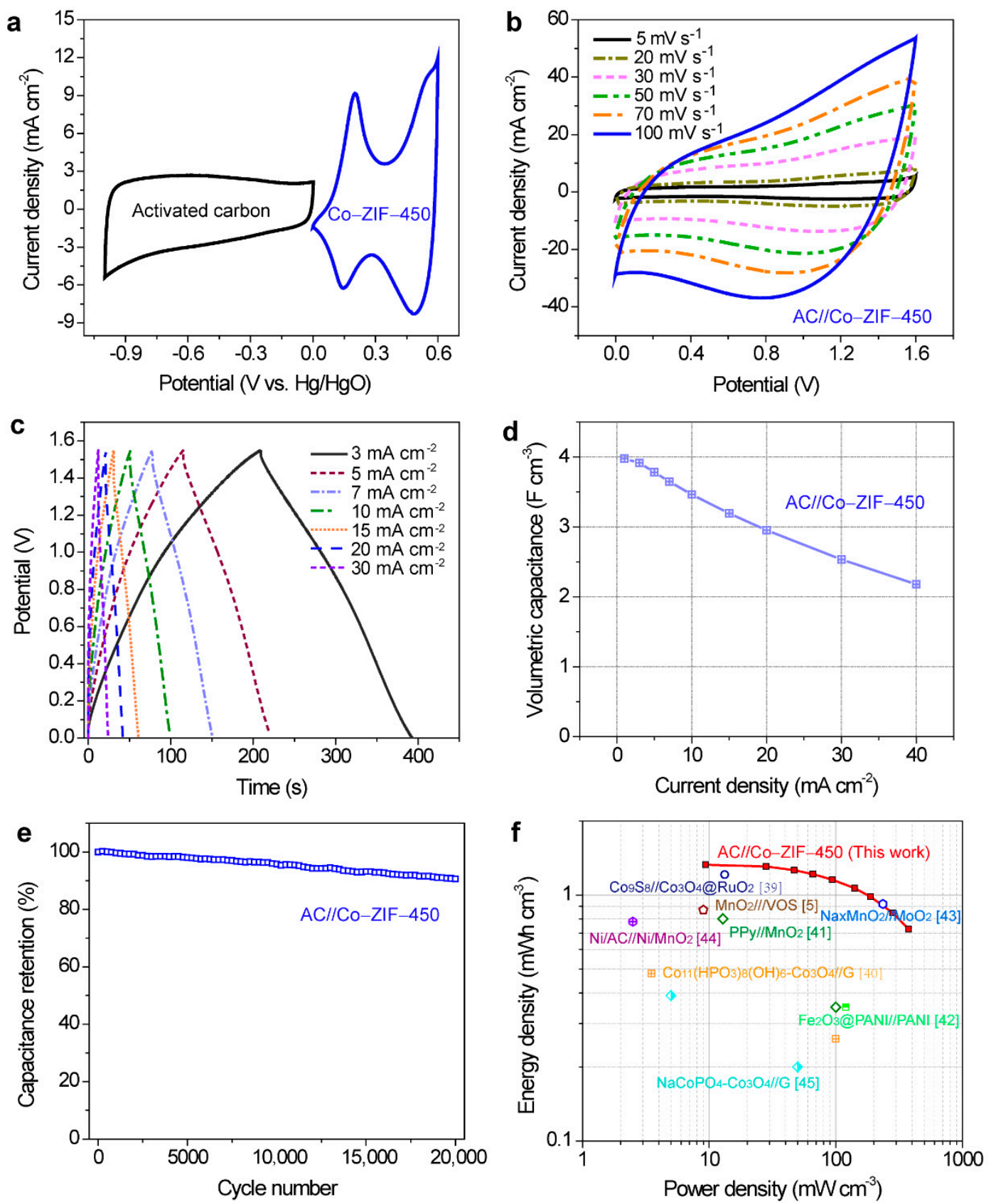

Figure 4. Electrochemical performances of the asymmetric supercapacitor prototype (AC//Co-ZIF-450) using $2 \mathrm{M}$ aqueous $\mathrm{KOH}$ electrolytes. (a) CV curves of Co-ZIF-450 (positive) and activated carbon (negative) at different potential windows. (b) $\mathrm{CV}$ curves at scan rates from 5 to $100 \mathrm{mV} \mathrm{s}^{-1}$. (c) Galvanostatic charge and discharge curves at current densities from 3 to $30 \mathrm{~mA} \mathrm{~cm}^{-2}$. (d) Volumetric capacitances as a function of current density. (e) Cycling stability during 20,000 charge and discharge cycles. (f) The Ragone plots comparing the energy and power densities of our device to selected previously demonstrated asymmetric supercapacitors. The red line is a guide.

\section{Conclusions}

In summary, this work demonstrates the synthesis of cobalt-incorporated, $\mathrm{N}$-doped nanoporous carbon nanocuboids via chemical bath deposition of $\mathrm{Co}-\mathrm{ZIF}$ and thermal annealing at $450{ }^{\circ} \mathrm{C}$. The highly conductive Co metal and $\mathrm{N}$-doped carbon network facilitated electron transport within the electrode, and the nanopores of each carbon nanocuboid functioned as electrolyte reservoirs that reduced ion diffusion distance from the electrolyte to electrode surfaces. Both factors contributed to the promising 
charge-storage performance of Co-ZIF-450. This electrode exhibited an areal capacitance of $1177 \mathrm{mF}$ $\mathrm{cm}^{-2}$ at the current density of $1 \mathrm{~mA} \mathrm{~cm}^{-2}$, which was 2 and 30 times higher than those of Co-ZIF-350 and Co-ZIF-550, respectively. Additionally, Co-ZIF-450 also displayed cycling stability with $94 \%$ capacitance retention after 20,000 consecutive charge-discharge cycles. By coupling with an activated carbon negative electrode, Co-ZIF-450 is a promising positive electrode in an asymmetric device prototype. The prototype delivered a volumetric energy density of $1.32 \mathrm{mWh} \mathrm{cm}^{-3}$ at the volumetric power density of $9.4 \mathrm{~mW} \mathrm{~cm}^{-3}$, outperforming other state-of-the-art supercapacitors with comparable volumes. This work highlights the functionality of metal-organic frameworks as precursors to highly porous metal oxide-carbon composite supercapacitor electrodes. These electrodes seamlessly integrate the merits of both pseudocapacitive and electrical double layer capacitive materials. Besides electrochemical energy storage demonstrated herein, we believe that the nanoporous Co-ZIF-based composites could be useful in a broad range of energy storage and conversion techniques, such as rechargeable batteries.

Supplementary Materials: The following are available online at http://www.mdpi.com/2079-4991/9/8/1110/s1, Figure S1: A side-view SEM image of the Co-ZIF; Figure S2: (a) SEM image and (b) carbon, (c) nitrogen, (d) oxygen, and (e) cobalt elemental mappings of Co-ZIF-450. Scale bar in (a): $5 \mu \mathrm{m}$. Figure S3: (a) Calibration curve of solution absorbance with various MB concentrations. (b) UV-vis spectra collected for Co-ZIF-350, Co-ZIF-450, and Co-ZIF-550. Figure S4: Gravimetric capacitances of Co-ZIF-X as a function of current densities; Figure S5: Cycling stability performances of Co-ZIF-350 and Co-ZIF-550. Figure S6: (a) CV curve and (b) constant-current charge and discharge profiles of the AC negative electrode. Figure S7: Cyclic voltammograms of AC//Co-ZIF-350, AC//Co-ZIF-450 and AC//Co-ZIF-550 at $50 \mathrm{mV} \mathrm{s}^{-1}$.

Author Contributions: Y.S. and M.Z. contributed equally to this work. Y.S. and M.Z. designed, performed all the experiments and wrote the manuscript draft; T.L. (Tianyu Liu), T.L. (Tianjiao Li) and D.G. analyzed the data. T.L. (Tianyu Liu), D.G., and X.-X.L. revised the manuscript with inputs from other authors.

Funding: This work was financially supported by National Natural Science Foundation of China (51804066, 51604067 and 21673035), China Postdoctoral Science Foundation (grant number: 2018M630294, 2015M580228, and 2019T120214), and Fundamental Research Funds for the Central Universities (N170503008).

Conflicts of Interest: The authors declare no conflict of interests.

\section{References}

1. Gao, J.; Zhang, X.; Yang, J.; Zhou, J.; Tong, M.; Jin, Q.; Dai, F.; Li, G. Ethylenediamine-catalyzed preparation of nitrogen-doped hierarchically porous carbon aerogel under hypersaline condition for high-performance supercapacitors and organic solvent absorbents. Nanomaterials 2019, 9, 771. [CrossRef] [PubMed]

2. Geng, L.; Yan, F.; Dong, C.; An, C. Design and regulation of novel $\mathrm{MnFe}_{2} \mathrm{O}_{4} @ \mathrm{C}$ nanowires as high performance electrode for supercapacitor. Nanomaterials 2019, 9, 777. [CrossRef] [PubMed]

3. Zeng, Y.; Lai, Z.; Han, Y.; Zhang, H.; Xie, S.; Lu, X. Oxygen-vacancy and surface modulation of ultrathin nickel cobaltite nanosheets as a high-energy cathode for advanced $\mathrm{Zn}$-ion batteries. Adv. Mater. 2018, 1802396. [CrossRef] [PubMed]

4. Zeng, Y.; Lin, Z.; Wang, Z.; Wu, M.; Tong, Y.; Lu, X. In situ activation of 3D porous Bi/carbon architectures: Toward high-energy and stable nickel-bismuth batteries. Adv. Mater. 2018, 30, 1707290. [CrossRef] [PubMed]

5. Zhai, T.; Lu, X.; Ling, Y.; Yu, M.; Wang, G.; Liu, T.; Liang, C.; Tong, Y.; Li, Y. A new benchmark capacitance for supercapacitor anodes by mixed-valence sulfur-doped $\mathrm{V}_{6} \mathrm{O}_{13-x}$. Adv. Mater. 2014, 26, 5869-5875. [CrossRef] [PubMed]

6. Liu, T.; Zhou, Z.; Guo, Y.; Guo, D.; Liu, G. Block copolymer derived uniform mesopores enable ultrafast electron and ion transport at high mass loadings. Nat. Commun. 2019, 10, 675. [CrossRef] [PubMed]

7. Song, Y.; Liu, T.; Yao, B.; Li, M.; Kou, T.; Huang, Z.H.; Feng, D.Y.; Wang, F.; Tong, Y.; Liu, X.X.; et al. Ostwald ripening improves rate capability of high mass loading manganese oxide for supercapacitors. ACS Energy Lett. 2017, 2, 1752-1759. [CrossRef]

8. Yao, B.; Chandrasekaran, S.; Zhang, J.; Xiao, W.; Qian, F.; Zhu, C.; Duoss, E.B.; Spadaccini, C.M.; Worsley, M.A.; $\mathrm{Li}, \mathrm{Y}$. Efficient 3D printed pseudocapacitive electrodes with ultrahigh $\mathrm{MnO}_{2}$ loading. Joule 2019, 3, 459-470. [CrossRef] 
9. Song, Y.; Liu, T.; Li, M.; Yao, B.; Kou, T.; Feng, D.; Wang, F.; Tong, Y.; Liu, X.X.; Li, Y. Engineering of mesoscale pores in balancing mass loading and rate capability of hematite films for electrochemical capacitors. Adv. Energy Mater. 2018, 8, 1801784. [CrossRef]

10. Sun, S.; Zhai, T.; Liang, C.; Savilov, S.V.; Xia, H. Boosted crystalline/amorphous $\mathrm{Fe}_{2} \mathrm{O}_{3-\delta}$ core/shell heterostructure for flexible solid-state pseudocapacitors in large scale. Nano Energy 2018, 45, 390-397. [CrossRef]

11. Lu, X.; Zeng, Y.; Yu, M.; Zhai, T.; Liang, C.; Xie, S.; Balogun, M.S.; Tong, Y. Oxygen-deficient hematite nanorods as high-performance and novel negative electrodes for flexible asymmetric supercapacitors. Adv. Mater. 2014, 26, 3148-3155. [CrossRef] [PubMed]

12. Yao, B.; Huang, L.; Zhang, J.; Gao, X.; Wu, J.; Cheng, Y.; Xiao, X.; Wang, B.; Li, Y.; Zhou, J. Flexible transparent molybdenum trioxide nanopaper for energy storage. Adv. Mater. 2016, 28, 6353-6358. [CrossRef] [PubMed]

13. Zhang, M.Y.; Song, Y.; Guo, D.; Yang, D.; Sun, X.; Liu, X.X. Strongly coupled polypyrrole/molybdenum oxide hybrid films via electrochemical layer-by-layer assembly for pseudocapacitors. J. Mater. Chem. A 2019, 7, 9815-9821. [CrossRef]

14. Geng, J.W.; Ye, Y.J.; Guo, D.; Liu, X.X. Concurrent electropolymerization of aniline and electrochemical deposition of tungsten oxide for supercapacitor. J. Power Sources 2017, 342, 980-989. [CrossRef]

15. Deng, J.; Kang, L.; Bai, G.; Li, Y.; Li, P.; Liu, X.; Yang, Y.; Gao, F.; Liang, W. Solution combustion synthesis of cobalt oxides $\left(\mathrm{Co}_{3} \mathrm{O}_{4}\right.$ and $\left.\mathrm{Co}_{3} \mathrm{O}_{4} / \mathrm{CoO}\right)$ nanoparticles as supercapacitor electrode materials. Electrochim. Acta 2014, 132, 127-135. [CrossRef]

16. Zhai, T.; Wan, L.; Sun, S.; Chen, Q.; Sun, J.; Xia, Q.; Xia, H. Phosphate ion functionalized $\mathrm{Co}_{3} \mathrm{O}_{4}$ ultrathin nanosheets with greatly improved surface reactivity for high performance pseudocapacitors. Adv. Mater. 2017, 29, 1604167. [CrossRef] [PubMed]

17. Augustyn, V.; Simon, P.; Dunn, B. Pseudocapacitive oxide materials for high-rate electrochemical energy storage. Energy Env. Sci. 2014, 7, 1597. [CrossRef]

18. Liu, C.; Chen, W.; Hong, S.; Pan, M.; Jiang, M.; Wu, Q.; Mei, C. Fast microwave synthesis of hierarchical porous carbons from waste palm boosted by activated carbons for supercapacitors. Nanomaterials 2019, 9, 405. [CrossRef] [PubMed]

19. Tan, Z.; Yu, F.; Liu, L.; Jia, X.; Lv, Y.; Chen, L.; Xu, Y.; Shi, Y.; Guo, X. Cu-doped porous carbon derived from heavy metal-contaminated sewage sludge for high-performance supercapacitor electrode materials. Nanomaterials 2019, 9, 892. [CrossRef]

20. Li, Q.; Wang, Z.L.; Li, G.R.; Guo, R.; Ding, L.X.; Tong, Y.X. Design and synthesis of $\mathrm{MnO}_{2} / \mathrm{Mn} / \mathrm{MnO}_{2}$ sandwich-structured nanotube arrays with high supercapacitive performance for electrochemical energy storage. Nano Lett. 2012, 12, 3803-3807. [CrossRef]

21. Zhang, H.; Xiao, W.; Zhou, W.; Chen, S.; Zhang, Y. Hierarchical porous carbon derived from Sichuan pepper for high-performance symmetric supercapacitor with decent rate capability and cycling stability. Nanomaterials 2019, 9, 553. [CrossRef] [PubMed]

22. Lu, X.; Yu, M.; Zhai, T.; Wang, G.; Xie, S.; Liu, T.; Liang, C.; Tong, Y.; Li, Y. High energy density asymmetric quasi-solid-state supercapacitor based on porous vanadium nitride nanowire anode. Nano Lett. 2013, 13, 2628-2633. [CrossRef] [PubMed]

23. Zhang, F.; Liu, T.; Li, M.; Yu, M.; Luo, Y.; Tong, Y.; Li, Y. Multiscale pore network boosts capacitance of carbon electrodes for ultrafast charging. Nano Lett. 2017, 17, 3097-3104. [CrossRef] [PubMed]

24. Wang, S.; Chen, M.; Xie, Y.; Fan, Y.; Wang, D.; Jiang, J.J.; Li, Y.; Grutzmacher, H.; Su, C.Y. Nanoparticle cookies derived from metal-organic frameworks: Controlled synthesis and application in anode materials for lithium-ion batteries. Small 2016, 12, 2365-2375. [CrossRef] [PubMed]

25. Zhao, R.; Liang, Z.; Zou, R.; Xu, Q. Metal-organic frameworks for batteries. Joule 2018, 2, $2235-2259$. [CrossRef]

26. Torrisi, V.; Ruffino, F. Metal-polymer nanocomposites:(Co-)evaporation/(Co)sputtering approaches and electrical properties. Coatings 2015, 5, 378-424. [CrossRef]

27. Peng, C.; Zhang, S.; Jewell, D.; Chen, G. Carbon nanotube and conducting polymer composites for supercapacitors. Prog. Nat. Sci. 2008, 18, 777-788. [CrossRef]

28. Fang, G.; Zhou, J.; Liang, C.; Pan, A.; Zhang, C.; Tang, Y.; Tan, X.; Liu, J.; Liang, S. MOFs nanosheets derived porous metal oxide-coated three-dimensional substrates for lithium-ion battery applications. Nano Energy 2016, 26, 57-65. [CrossRef] 
29. Liu, Q.; Low, Z.X.; Feng, Y.; Leong, S.; Zhong, Z.; Yao, J.; Hapgood, K.; Wang, H. Direct conversion of two-dimensional ZIF-L film to porous $\mathrm{ZnO}$ nano-sheet film and its performance as photoanode in dye-sensitized solar cell. Micropor. Mesopor. Mater. 2014, 194, 1-7. [CrossRef]

30. Biesinger, M.C.; Payne, B.P.; Grosvenor, A.P.; Lau, L.W.M.; Gerson, A.R.; Smart, R.S.C. Resolving surface chemical states in XPS analysis of first row transition metals, oxides and hydroxides: $\mathrm{Cr}, \mathrm{Mn}, \mathrm{Fe}, \mathrm{Co}$ and $\mathrm{Ni}$. Appl. Surf. Sci. 2011, 257, 2717-2730. [CrossRef]

31. Ma, X.; Zhou, Y.X.; Liu, H.; Li, Y.; Jiang, H.L. A MOF-derived Co-CoO@N-doped porous carbon for efficient tandem catalysis: Dehydrogenation of ammonia borane and hydrogenation of nitro compounds. Chem. Commun. 2016, 52, 7719-7722. [CrossRef] [PubMed]

32. Zhou, Y.X.; Chen, Y.Z.; Cao, L.; Lu, J.; Jiang, H.L. Conversion of a metal-organic framework to N-doped porous carbon incorporating Co and CoO nanoparticles: Direct oxidation of alcohols to esters. Chem. Commun. 2015, 51, 8292-8295. [CrossRef] [PubMed]

33. Yang, D.; Song, Y.; Ye, Y.J.; Zhang, M.; Sun, X.; Liu, X.X. Boosting the pseudocapacitance of nitrogen-rich carbon nanorod arrays for electrochemical capacitors. J. Mater. Chem. A 2019, 7, 12086-12094. [CrossRef]

34. Yang, K.; Guo, Q.; Li, H.; Hao, X.; Ma, Y.; Yang, M.; Zhai, T.; Savilov, S.; Lunin, V.; Xia, H. Highly efficient sol-gel synthesis for ZnS@N, S co-doped carbon nanosheets with embedded heterostructure for sodium ion batteries. J. Power Sources 2018, 402, 340-344. [CrossRef]

35. Pang, H.; Gao, F.; Chen, Q.; Liu, R.; Lu, Q. Dendrite-like $\mathrm{Co}_{3} \mathrm{O}_{4}$ nanostructure and its applications in sensors, supercapacitors and catalysis. Dalton Trans. 2012, 41, 5862-5868. [CrossRef] [PubMed]

36. Lee, D.Y.; Shinde, D.V.; Kim, E.K.; Lee, W.; Oh, I.W.; Shrestha, N.K.; Lee, J.K.; Han, S.H. Supercapacitive property of metal-organic-frameworks with different pore dimensions and morphology. Micropor. Mesopor. Mater. 2013, 171, 53-57. [CrossRef]

37. Meng, F.; Fang, Z.; Li, Z.; Xu, W.; Wang, M.; Liu, Y.; Zhang, J.; Wang, W.; Zhao, D.; Guo, X. Porous $\mathrm{Co}_{3} \mathrm{O}_{4}$ materials prepared by solid-state thermolysis of a novel Co-MOF crystal and their superior energy storage performances for supercapacitors. J. Mater. Chem. A 2013, 1, 7235. [CrossRef]

38. Wang, G.; Wang, H.; Lu, X.; Ling, Y.; Yu, M.; Zhai, T.; Tong, Y.; Li, Y. Solid-state supercapacitor based on activated carbon cloths exhibits excellent rate capability. Adv. Mater. 2014, 26, 2676-2682. [CrossRef] [PubMed]

39. Xu, J.; Wang, Q.; Wang, X.; Xiang, Q.; Liang, B.; Chen, D.; Shen, G. Flexible asymmetric supercapacitors based upon $\mathrm{Co}_{9} \mathrm{~S}_{8}$ nanorod $/ / \mathrm{Co}_{3} \mathrm{O}_{4} @ \mathrm{RuO}_{2}$ nanosheet arrays on carbon cloth. Acs Nano 2013, 7, 5453-5462. [CrossRef] [PubMed]

40. Zhang, Y.; Zheng, M.; Qu, M.; Sun, M.; Pang, H. Core-shell $\mathrm{Co}_{11}\left(\mathrm{HPO}_{3}\right)_{8}(\mathrm{OH})_{6}-\mathrm{Co}_{3} \mathrm{O}_{4}$ hybrids for high-performance flexible all-solid-state asymmetric supercapacitors. J. Alloy. Compd. 2015, 651, $214-221$. [CrossRef]

41. Feng, D.Y.; Song, Y.; Huang, Z.H.; Xu, X.X.; Liu, X.X. Rate capability improvement of polypyrrole via integration with functionalized commercial carbon cloth for pseudocapacitor. J. Power Sources 2016, 324, 788-797. [CrossRef]

42. Lu, X.F.; Chen, X.Y.; Zhou, W.; Tong, Y.X.; Li, G.R. $\alpha-\mathrm{Fe}_{2} \mathrm{O}_{3} @ P A N I$ core-shell nanowire arrays as negative electrodes for asymmetric supercapacitors. ACS Appl. Mater. Interf. 2015, 7, 14843-14850. [CrossRef] [PubMed]

43. Lu, X.F.; Huang, Z.X.; Tong, Y.X.; Li, G.R. Asymmetric supercapacitors with high energy density based on helical hierarchical porous $\mathrm{Na}_{x} \mathrm{MnO}_{2}$ and $\mathrm{MoO}_{2}$. Chem. Sci. 2016, 7, 510-517. [CrossRef] [PubMed]

44. Zhang, L.; Zhu, P.; Zhou, F.; Zeng, W.; Su, H.; Li, G.; Gao, J.; Sun, R.; Wong, C.P. Flexible asymmetrical solid-state supercapacitors based on laboratory filter paper. ACS Nano 2016, 10, 1273-1282. [CrossRef] [PubMed]

45. Wei, C.; Cheng, C.; Zhou, B.; Yuan, X.; Cui, T.; Wang, S.; Zheng, M.; Pang, H. Hierarchically porous $\mathrm{NaCoPO}_{4}-\mathrm{Co}_{3} \mathrm{O}_{4}$ hollow microspheres for flexible asymmetric solid-state supercapacitors. Part. Part. Syst. Char. 2015, 32, 831-839. [CrossRef]

(C) 2019 by the authors. Licensee MDPI, Basel, Switzerland. This article is an open access article distributed under the terms and conditions of the Creative Commons Attribution (CC BY) license (http://creativecommons.org/licenses/by/4.0/). 